\title{
Nasal contribution to exhaled nitric oxide during exhalation against resistance or during breath holding
}

\author{
Sergei A Kharitonov, Peter J Barnes
}

\begin{abstract}
Background - The concentration of nitric oxide (NO) is increased in the exhaled air of patients with inflammation of the airways, suggesting that this may be a useful measurement to monitor inflammation in diseases such as asthma. However, there have been concerns that exhaled NO may be contaminated by the high concentrations of NO derived from the upper airways, and that this may account for differences in reported values of exhaled NO using different techniques. A study was performed, with argon as a tracer, to determine the extent of nasal contamination of exhaled NO using different expiratory manoeuvres.

Methods - Exhaled and nasal NO were measured by a chemiluminescence analyser. Argon (4.8\%) was delivered continuously to the nose. Gas was sampled from the posterior oropharynx and argon and carbon dioxide were measured by mass spectrometry at the same time as NO.

Results - During a single expiration against a low resistance and during breath holding there was no evidence for nasal contamination, whereas during exhalation without resistance argon concentration in the oropharynx was increased from $0.91 \%$ $(95 \%$ CI $0.84 \%$ to $0.98 \%)$ in ambient air to $1.28 \%(0.9 \%$ to $2.24 \%, \mathrm{p}<0.0001)$ during a single breath or $2.37 \%(2.29 \%$ to $2.51 \%$, $\mathbf{p}<0.0001$ ) during tidal breathing. Conclusions - Collection of exhaled NO in a reservoir during tidal breathing is likely to be contaminated by NO derived from the nose and this may underestimate any increases in NO derived from the lower respiratory tract in inflammatory diseases. However, with slow expiration against a resistance and created back pressure to close the soft palate, there is no contamination of exhaled air which then reflects concentrations of NO in the lower airways.

(Thorax 1997;52:540-544)
\end{abstract}

Keywords: asthma, nitric oxide, upper respiratory tract.

Nitric oxide (NO) has been detected in the exhaled air of normal humans ${ }^{1-3}$ and its concentration is increased in inflammatory airway diseases such as asthma, ${ }^{4-7}$ bronchiectasis, ${ }^{8}$ and after viral infections. ${ }^{9}$ The increase in exhaled
NO may reflect increased expression of inducible NO synthase at the sites of inflammation, ${ }^{10}$ suggesting that measurement of exhaled NO may provide a non-invasive means of monitoring airway inflammation and its control with anti-inflammatory drugs. ${ }^{11}$ Glucocorticoids inhibit the expression of inducible NO synthase and both oral and inhaled glucocorticoids reduce the concentrations of exhaled NO in asthmatic patients. ${ }^{12}{ }^{13}$ Furthermore, when the dose of inhaled steroids is reduced in controlled asthmatic patients, exhaled NO increases before any fall in lung function or increase in asthma symptoms, suggesting that monitoring of exhaled NO may be useful in assessing asthma control. ${ }^{14}$

Several techniques have been used to measure exhaled NO and there are differences between laboratories in reported values of $\mathrm{NO}$ in exhaled air of normal and asthmatic patients. ${ }^{11}$ These techniques include collection of exhaled $\mathrm{NO}$ in a reservoir during tidal breathing or measurement of exhaled NO during a single expiration. Other factors such as breath holding and expiratory flow rate may also affect the measurement. ${ }^{15}$ It is important to standardise the measurement of exhaled NO if this technique is going to be widely used in clinical practice. A particular concern is that NO measured in exhaled air may be contaminated by NO derived from the nose and nasopharynx where much higher concentrations have been found. ${ }^{16-18}$ It has recently been shown that measurement of $\mathrm{NO}$ at the mouth during a single expiratory manoeuvre equates well with the concentrations of NO measured directly from the lower respiratory tract via a bronchoscope, suggesting that nasal contamination is unlikely to be a major problem with this technique. ${ }^{1920}$

In order to validate the measurement of exhaled NO further we have now used a nasally delivered tracer gas (argon) to study nasal contamination of expired air during various expiratory manoeuvres.

\section{Methods}

MEASUREMENT OF EXHALED AND NASAL NO

Exhaled NO was measured by a chemiluminescence analyser (Model LR2000, Logan Research, Rochester, UK) with a sensitivity from $1 \mathrm{ppb}$ to $100 \mathrm{ppm}$ of $\mathrm{NO}$, accuracy $\pm 0.5 \mathrm{ppb}$, and a response time of less than two seconds to $90 \%$ of full scale. In addition, the analyser also measured carbon dioxide (range $0-10 \%$, accuracy $\pm 0.1 \%$, response time 


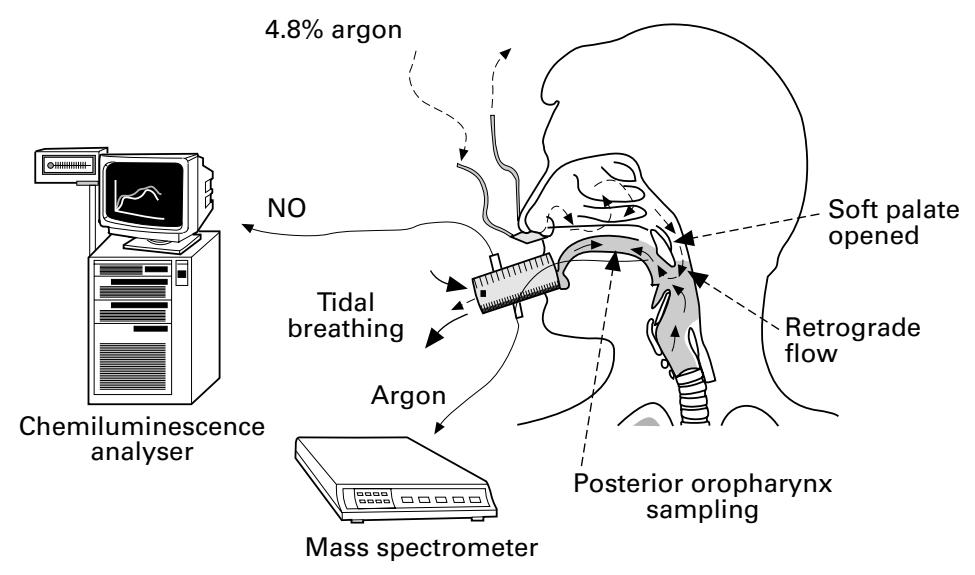

Figure 1 Simultaneous measurement of nitric oxide (NO) at the mouth and argon at the oropharynx during continuous delivery of argon to the nose. During tidal breathing the soft palate allows communication between upper and lower respiratory tracts and argon can therefore be detected in exhaled air. When expiring against a resistance the soft palate is raised, preventing contamination of exhaled air with argon.

$200 \mathrm{~ms}$ to $90 \%$ of full scale), expiratory flow and pressure, and exhaled volume in real time. The analyser was fitted with a biofeedback display unit to provide visual guidance for the subject to maintain the pressure and exhalation flow within a certain range $(3(0.4) \mathrm{mm} \mathrm{Hg}$ and 6 (0.09) $1 / \mathrm{min}$ for end exhaled NO measurements), thus improving test repeatability and enhancing patient cooperation. Pressure created in the mouthpiece, and subsequently in the reaction chamber, varied non-significantly and therefore caused negligible change $(<0.1$ $\mathrm{ppb}$ ) in NO readings. The sampling rate through the reaction chamber of the analyser was $250 \mathrm{ml} / \mathrm{min}$ for all measurements. The analyser was calibrated daily using NO-free certified compressed air to set absolute zero followed by a certified concentration of $\mathrm{NO}$ in nitrogen of $91 \mathrm{ppb}$ and $500 \mathrm{ppb}$ (British Oxygen Corporation Special Gases, Guildford, UK) and certified 5\% carbon dioxide (BOC). The linearity was tested with 31 serial dilutions from 0.6 to $2500 \mathrm{ppb}$ of the NO test gas. Repeated serial dilutions showed that observed $\mathrm{NO}$ values obtained by the analyser varied linearly with the predicted NO values, and all points fell along the line of identity. Ambient air NO level was recorded and the absolute zero was adjusted prior to all measurements.

For the end exhaled NO measurements subjects exhaled slowly from total lung capacity (TLC) up to 30 seconds with an exhalation flow rate of $6(0.09) 1 / \mathrm{min}$, bypassing the analyser and thus with a low resistance to flow. $\mathrm{NO}$ was sampled from a side arm attached to the mouthpiece. The mean value of the previous 100 measurements, acquired with an interval of $25 \mathrm{~Hz}$, was taken from the point on the $\mathrm{NO}$ trace corresponding to the $\mathrm{CO}_{2}$ reading of $5-6 \%$. Results of the analyses were computed and graphically displayed on a plot of NO and $\mathrm{CO}_{2}$ concentrations, pressure, and flow against time.

SUBJECTS

Seven non-smoking, non-atopic normal subjects (five men) of mean (SD) age 30 (4) years participated in the study. None had a history of respiratory or cardiovascular disease or was receiving long term medication. Spirometric measurements showed a mean forced expiratory volume in one second of 101 (3)\% predicted.

\section{PROTOCOL}

We studied whether the nasal cavities and the pharynx were in communication during a slow single exhalation against resistance or during tidal breathing or breath holding by sampling the posterior pharynx whilst the nasal cavities were gently flushed with a gas mixture containing $4.8 \%$ argon (fig 1). Argon was chosen as the marker for nasal contamination because of its inert nature, low ambient concentration $(<1 \%)$, and better mass spectrometric signal than helium.

The subjects were asked to produce four manoeuvres: (1) slow exhalation with a flow rate of $6(0.09) 1 / \mathrm{min}$ through the mouthpiece against a resistance of $3(0.4) \mathrm{mm} \mathrm{Hg}$; (2) unobstructed exhalation through the standard spirometric mouthpiece $(27 \mathrm{~mm}$ inner diameter) with no resistance to exhalation as it is wider than an average trachea; (3) tidal breathing through the spirometric mouthpiece for 50 seconds; (4) breath holding for 30 seconds.

$\mathrm{NO}$, argon, and $\mathrm{CO}_{2}$ concentrations in the exhaled air were measured simultaneously during exhalation against a resistance and tidal breathing manoeuvres. Only argon and $\mathrm{CO}_{2}$ concentrations were assessed during breath holding. Each manoeuvre was repeated three times. The subjects were asked to make two exhalations without resistance, separated by a single inhalation of ambient air. The nasal cavities were gently flushed (flow $21 / \mathrm{min}$ ) with the gas mixture containing $4.8 \%$ argon, $15 \%$ $\mathrm{O}_{2}, 4.7 \% \mathrm{CO}_{2}$, balanced with $\mathrm{N}_{2}$ before and during exhalation. Fine tubing with $0.5 \mathrm{~mm}$ internal diameter was put into the posterior oropharynx at the level of the tonsils (local anaesthetic was not required) to sample the posterior oropharyngeal mixed air (flow $200 \mathrm{ml} / \mathrm{min}$ ) directly into the mass spectrometer (Model MGA 200, Airspec Ltd, Biggin Hill, UK) with an accuracy of $\pm 0.1 \%$ for argon and $\mathrm{CO}_{2}$ assessment. Mean values of the three $\mathrm{NO}$ and argon concentrations were calculated. All the measurements were made on the same day when the ambient, and therefore the exhaled argon concentration, were $0.9 \%$.

\section{DATA ANALYSIS}

The statistical analyses used the Student's paired $t$ test for the comparison between the start and end of each exhalation, with the level of significance taken as $5 \%$.

\section{Results}

MEASUREMENT OF EXHALED GASES

Simultaneous measurements of $\mathrm{NO}$ and argon were made during the exhalation against a resistance. As the nasal cavities were flushed 
A

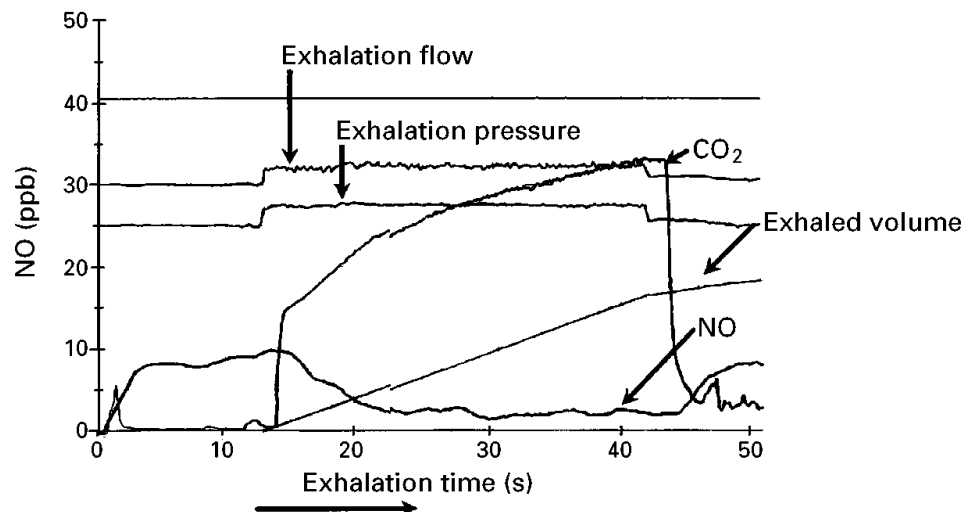

B

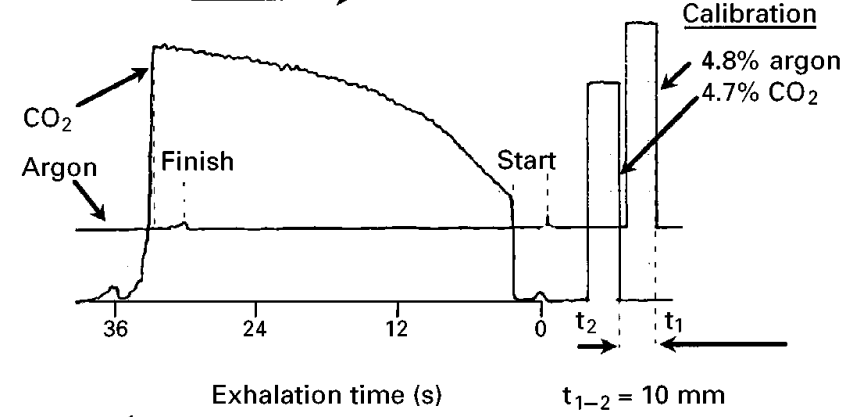

Figure 2 Original trace showing simultaneous measurement of $(A)$ exhaled nitric oxide (NO) and carbon dioxide $\left(\mathrm{CO}_{2}\right)$ and $(\mathrm{B})$ argon and $\mathrm{CO}_{2}$ measured at the posterior nasopharynx by mass spectrometry after a single expiration against resistance. Note that there is no increase in argon concentration during the manoeuvre.
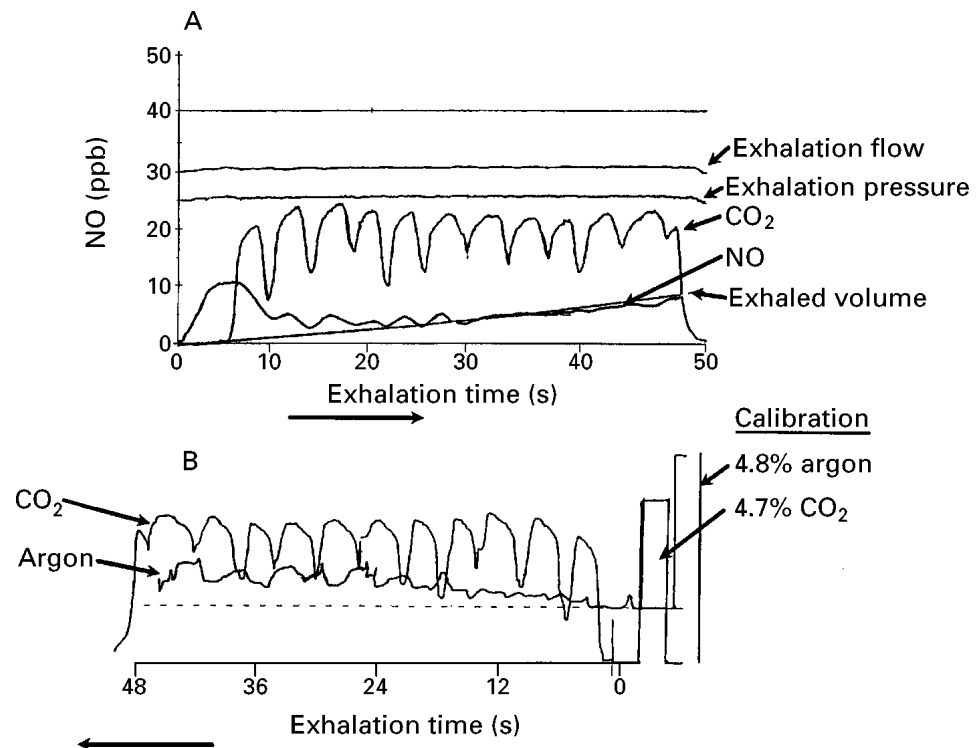

Figure 3 Trace showing (A) exhaled nitric oxide (NO) and carbon dioxide $\left(\mathrm{CO}_{2}\right)$ during tidal breathing and $(B)$ exhaled argon and $\mathrm{CO}_{2}$ measured by mass spectrometry with argon delivered to the nose. There is a progressive increase in the exhaled argon concentration during tidal breathing. from the remainder of the respiratory tract by elevation of the soft palate due to positive back pressure, there was no increase in argon concentration (fig 2). The mean argon concentration did not change during the exhalation: $0.91 \%(95 \%$ confidence interval (CI) $0.84 \%$ to $0.98 \%)$ at the start and $0.91 \%(95 \%$ CI $0.87 \%$ to $0.95 \%$ ) at the end of exhalation $(p>0.05)$. End exhaled NO levels were 6.3 (1.01) ppb.

Exhaled air measured during a single exhalation without resistance and with no back pressure was contaminated with argon derived from the nasal cavities due to soft palate opening at the start of exhalation $(0.91 \%(95 \%$ CI $0.84 \%$ to $0.98 \%$ ), increasing to $1.28 \%$ (95\% CI $0.9 \%$ to $2.24 \%$ ) at the end of the second exhalation ( $\mathrm{p}<0.0001)$. Thus, in subjects breathing through the mouth freely, nasopharyngeal NO is added to the mouth exhalate which is reflected by an increase in argon concentration when compared with the ambient level of argon.

There was an increase in the argon concentration from $0.91 \%$ (95\% CI 0.84 to $0.98 \%$ ) to $2.37 \%$ (95\% CI 2.29 to $2.5 \%$ ) during tidal breathing $(\mathrm{p}<0.0001)$. NO levels were also significantly higher at the end of tidal breathing (7.2 (1.34) ppb compared with 3.2 (0.87) ppb at the beginning, $\mathrm{p}<0.001$ ), presumably because of nasal contamination (fig 3 ).

EFFECT OF BREATH HOLDING

Direct sampling of the argon concentration in the posterior pharynx during breath holding revealed complete closure of the soft palate. The $\mathrm{CO}_{2}$ levels gradually increased up to $0.3-$ $0.4 \%$ over $25-30$ seconds of breath holding, reflecting the mixed air in the posterior pharynx. There was no increase in argon concentration throughout the breath hold from $0.91 \%$ (95\% CI $0.84 \%$ to $0.98 \%$ ) to $0.92 \%$ ( $95 \%$ CI $0.87 \%$ to $0.97 \%)$, p >0.05, except the small $(0.1 \%)$ peak at the end of breath holding when the mass spectrometer sampling tube was removed from the mouth.

\section{Discussion}

There are three commonly used approaches to the measurement of exhaled NO: (1) collection of the exhaled air into a reservoir during tidal breathing or single exhalation with analysis thereafter; (2) sampling from a mixing chamber at the expiratory side of the mouthpiece during tidal breathing or via a side arm from the mouthpiece until steady state levels are achieved; (3) single slow exhalation through the mouthpiece with side arm sampling or directly into the analyser.

A reservoir collection method might be preferred for measurement of NO production at rest, during exercise, or when the chemiluminescence analyser is not available on site. It has been shown that the material of which the reservoirs are made (polyethylene or NO impermeable mylar) does not substantially affect the results. ${ }^{20-22}$ Indeed, Schilling et al have shown no change in NO concentration 


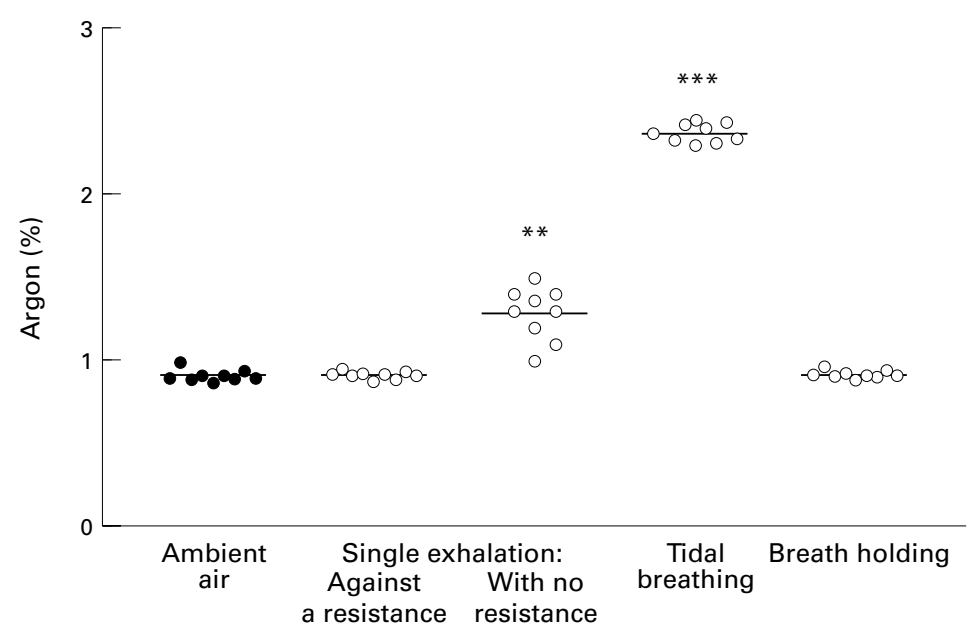

Figure 4 Exhaled argon concentration (\%) in ambient air and in exhaled air after continuous delivery to the nose of argon (4.8\%) during exhalation against resistance, exhalation without resistance, during tidal breathing, and during breath holding. Mean (SE) values of seven normal subjects are shown; $* * p<0.002, * * * p<0.0001$ compared with ambient levels. sampling with a flow rate of $250 \mathrm{ml} / \mathrm{min}$ during breath holding when the soft palate is closed. ${ }^{18}$ Soft palate closure has been confirmed by the absence of $\mathrm{CO}_{2}$ and argon traces in the nasal sample. High nasal levels have been obtained during direct binasal sampling whilst mouth breathing (394 (23) $\mathrm{ppb})^{25}$ and via a bronchoscope directly from the nasopharynx (334 (52) $\mathrm{ppb}$ ), with a further increase to $>1000$ ppb during breath holding when the soft palate was closed. However, the use of an air stream of $2-51 / \mathrm{min}$ through the nose reduced nasal NO levels to $105 \mathrm{ppb}$ during mouth breathing and $140 \mathrm{ppb}$ whilst breath holding, ${ }^{4}$ implying that there was a dilution due to the air stream application and a mixing of "high nasal NO" with "low exhaled NO".

At rest, release of NO from the nasal passages is approximately $40-120$ times that of the rest of the respiratory tract. These high NO levels suggest that NO in exhaled air is generated mainly in the nasal mucosa or nasopharynx. ${ }^{42}$ It is more likely that the presence and the extent of the nasal contribution depends upon the type of exhalation manoeuvre. Exhaled NO levels during tidal nasal breathing were 2-3 times higher than during mouth breathing. ${ }^{42}$ During assisted ventilation via the nose exhaled NO was four times higher than during spontaneous mouth breathing and 13 times lower when any nasal contribution was completely abolished by spontaneous breathing via tracheostomy. ${ }^{25}$ There is a significant nasal contribution to exhaled NO in normal subjects whilst tidal breathing with noseclips in place. ${ }^{22}$ As we have demonstrated, with simultaneous $\mathrm{NO}$ and argon measurements in the exhaled breath there was an increase in argon coming from the nasal passages during a single exhalation without resistance or during tidal breathing because of an opened soft palate. However, the same measurements did not show any trace of argon in the exhaled air when the subjects were using the slow exhalation manoeuvre against mild resistance (fig 4). Back pressure created by exhalation against resistance effectively kept the soft palate closed. Indeed, when the nasal contribution to mouth breathing was eliminated by voluntary soft palate closure or by applying the balloon occlusion method, exhaled NO from the mouth was reduced by half. ${ }^{22}$

Slow exhalation from vital capacity to residual volume through the mouthpiece, which inevitably creates resistance, appears to be the best manoeuvre to obtain the most reproducible NO samples, free of nasal contamination. Thus, using this technique several groups have obtained exhaled NO values that are in good agreement: 7 (4) ppb, ${ }^{22} 7$ (1) $\mathrm{ppb},{ }^{19}$ and $6(0.4) \mathrm{ppb}$, even though the latter was analysed from a reservoir. ${ }^{24}$ Exhalation against resistance closes the soft palate, hence abolishing nasal contamination. Indeed, as Kimberley et al have shown, there was no difference in exhaled NO measured either during slow exhalation against resistance (7 (4) $\mathrm{ppb}$ ) or after the nasopharynx was isolated by inflated balloon occlusion (7 (4) ppb). ${ }^{22}$ Further studies are needed to evaluate the pos- 
sible contamination of exhaled NO with NO derived from the oral cavity, oral pharynx and larynx, but the similarity between direct measurement of NO from the lower respiratory tract and exhaled NO suggests that this is likely to be minimal. ${ }^{1920}$

This work was supported by the British Lung Foundation.

1 Gustafsson LE, Leone AM, Persson M, Wiklund NP, Moncada $S$. Endogenous nitric oxide is present in the exhaled cada S. Endogenous nitric oxide is present in the exhaled
air of rabbits, guinea-pigs and humans. Biochem Biophys air of rabbits, guinea-pigs and

2 Borland C, Cox Y, Higenbottam T. Measurement of exhaled nitric oxide in man. Thorax 1993;48:1160-2

3 Leone AM, Gustafsson LE, Francis PL, Persson MG, Wiklund NP, Moncada S. Nitric oxide in exhaled breath in humans: direct GC-MS confirmation. Biochem Biophys Res Commun 1994;201:883-7.

4 Alving K, Weitzberg E, Lundberg JM. Increased amount of nitric oxide in exhaled air of asthmatics. Eur Respir f 1993; 6:1268-70.

5 Kharitonov SA, Yates D, Robbins RA, Logan-Sinclair R, Shinebourne E, Barnes PJ. Increased nitric oxide in exhaled air of asthmatic patients. Lancet 1994;343:133-5.

6 Persson MG, Zetterstrom O, Argenius V, Ihre E, Gustafsson LE. Single-breath oxide measurements in asthmatic patients and smokers. Lancet 1994;343:146-7.

7 Robbins RA, Floreani AA, von Essen SG, Sissin JH, Hill GE, Rubinstein I, et al. Measurement of exhaled nitric oxide by three different techniques. Am 7 Respir Crit Care Med 1996;153:1631-5.

8 Kharitonov SA, Wells AU, O'Connor BJ, Hansell DM, Cole PJ, Barnes PJ. Elevated levels of exhaled nitric oxide in bronchiectasis. Am f Respir Crit Care Med 1995;151: 1889-93.

9 Kharitonov SA, Yates D, Barnes PJ. Increased nitric oxide in exhaled air of normal human subjects with upper respiratory tract infections. Eur Respir f 1995;8:295-7.

10 Barnes PJ. Nitric oxide and airway disease. Ann Med 1995; 27:389-93.

11 Barnes PJ, Kharitonov SA. Exhaled nitric oxide: a new lung function test. Thorax 1996; 51:218-20.

12 Yates DH, Kharitonov SA, Robbins RA, Thomas PS, Barnes PJ. Effect of a nitric oxide synthase inhibitor and a gluco- corticosteroid on exhaled nitric oxide. Am $\mathcal{F}$ Respir Crit Care Med 1995;152:892-6.

13 Kharitonov SA, Yates DH, Barnes PJ. Regular inhaled budesonide decreases nitric oxide concentration in the exhaled air of asthmatic patients. Am $\mathcal{F}$ Respir Crit Care Med 1996;153:454-7.

14 Kharitonov SA, Yates DH, Chung KF, Barnes PJ. Changes in the dose of inhaled steroid affect exhaled nitric oxide levels in asthmatic patients. Eur f Respir Dis 1996;9: 196-201.

15 Persson MG, Wiklund NP, Gustafsson LE. Endogenous nitric oxide in single exhalation, and the change during exercise. Am Rev Respir Dis 1993;148:1210-4.

16 Gerlach H, Rossaint R, Pappert D, Knorr M, Falke KJ Autoinhalation of nitric oxide after endogenous synthesis in nasopharynx. Lancet 1994;343:518-9.

17 Lundberg JON, Weitzberg E, Nordvall SL, Kuylenstierna $\mathrm{R}$, Lundberg JM, Alving K. Primarily nasal origin of exhaled nitric oxide and absence in Kartagener's syndrome. Eur Respir 7 1994;8:1501-4.

18 Kharitonov SA, Rajakulasingam K, O'Connor BJ, Durham SR, Barnes PJ. Nasal nitric oxide is increased in patients with Barnes $P J$. Nasal nitric oxide is increased in patients by nasal glucocorticoids. F Allergy Clin Immunol 1997;99: by nasa

19 Kharitonov S, Chung KF, Evans DJ, O'Connor BJ, Barnes PJ. Increased exhaled nitric oxide in asthma is derived fo. Increased exhaled nitric oxide in asthma is derived Med 1996;153:1773-80.

20 Massaro AF, Mehta S, Lilly CM, Kobzik L, Reilly JJ, Drazen $\mathrm{JM}$. Elevated nitric oxide concentrations in isolated lower airway gas of asthmatic subjects. Am F Respir Crit Car Med 1996;153:1510-4.

21 Cremona G, Higenbottam T, Takao M, Hall L, Bower EA Exhaled nitric oxide in isolated pig lungs. $\mathcal{F}$ Appl Physio 1995;78:59-63.

22 Kimberley B, Nejadnik B, Giraud GD, Holden WE. Nasal contribution to exhaled nitric oxide at rest and during breath holding in humans. Am $\mathcal{F}$ Respir Crit Care Med 1996;153:829-36.

, Gyurech D, Marathia $\mathrm{K}$, Geroulanos S. Reduced endogenous nitric oxide in the exhaled air of smokers and hypertensioners. Eur Respir $f$ 1994;7:467-71.

24 Massaro AF, Gaston B, Kita D, Fanta C, Stamler J, Drazen M. Expired nitric oxide levels during treatment for acute asthma. Am f Respir Crit Care Med 1995;152:800-3.

25 Schedin U, Frostell C, Persson MG, Jakobsson J, Anderssson G, Gustafsson LE. Contribution from upper and lower airways to exhaled endogenous nitric oxide in humans. Acta Anaesthesiol Scand 1995;39:327-32. 